\title{
Consequences of shoot density and stiffness for ecosystem engineering by benthic macrophytes in flow dominated areas: a hydrodynamic flume study
}

\author{
G. Peralta ${ }^{1,2, *}$, L. A. van Duren ${ }^{1,3}$, E. P. Morris ${ }^{2}$, T. J. Bouma ${ }^{1}$ \\ ${ }^{1}$ Netherlands Institute of Ecology (KNAW-NIOO), Center for Estuarine and Marine Ecology, Korringaweg 7, \\ 4401 NT Yerseke, The Netherlands \\ ${ }^{2}$ Department of Biology, University of Cadiz, 11510 Puerto Real (Cadiz), Spain \\ ${ }^{3}$ Present address: DELTARES, PO Box 177, 2600 MH Delft, The Netherlands
}

\begin{abstract}
Within intertidal areas of European Atlantic coasts the distribution of the small seagrass Zostera noltii and the halophyte Spartina anglica can partially overlap, despite numerous biomechanical, demographic and ecophysiological differences. Both species are known to be ecosystem engineers that modify their habitat by reducing hydrodynamic energy within their canopies. In this study we investigate the influence of biomechanical (i.e. shoot flexibility) and demographic (i.e. shoot density) characteristics of these intertidal plants on their interaction with unidirectional currents to (1) understand their differences in ecosystem engineering capacity and (2) identify which physical traits explains these differences. In a flume tank, hydrodynamic variables were measured within transplanted $S$. anglica and $Z$. noltii meadows, and their corresponding simplified mimics. The results revealed that stiff canopies had a larger potential capacity (relative to flexible ones) to trap sediment, as in these vegetations velocity reduction within the canopy combined with a sufficient volumetric flow rate to provide sediment for settling. Flexible canopies were most efficient at reducing erosion by reconfiguration of their leaves. Shoot density increased the magnitude of these effects when values were moderate. However, the capacity to increase sediment accretion disappeared when the maximum velocity attenuation was reached and the flow of water was relocated on top of the canopy. These habitat modifications may provide ecological benefits for saltmarsh and seagrass species. For saltmarsh plants, the rigid shoots allow lateral expansion of their populations via increased sedimentation. For seagrasses, the dense and flexible shoots typical of temperate intertidal populations provide efficient protection from erosive forces, while at the same time helping to avoid stresses, such as drag forces and high sedimentation rates.
\end{abstract}

KEY WORDS: Ecosystem engineering - Habitat modification - Hydrodynamics · Seagrasses Salt marsh plants $\cdot$ Zostera noltii $\cdot$ Spartina anglica $\cdot$ Flume tank $\cdot$ ADV

\section{INTRODUCTION}

Mudflat-salt marsh boundaries offer a hostile environment for plant growth. Stresses such as salinity, inundation, anoxic sediments and hydrodynamic forces determine the establishment, survival and expansion of plants in these sea-land boundaries (Bruno 2000, van Katwijk et al. 2000). To cope with these stresses, plants must be able to tolerate the conditions and/or to reduce stress levels by modifying the abiotic environment. Biologically mediated modifications of the abiotic environment have previously been called ecosystem engineering (Jones et al. 1994). Most plant species that dominate the stressful estuarine intertidal areas are ecosystem engineers, in that they modify their environment via the interaction of their shoots with hydrodynamics. Interestingly, coexisting plant species living at this frontier between terrestrial and 
marine ecosystems can have marked biomechanical and physiological differences with important implications for their engineering capacity and the resulting feedback effects (Bouma et al. 2005).

On European Atlantic coasts, the pioneer areas of the stiff salt marsh species Spartina anglica often overlap with the beginning of the distribution area of the highly flexible seagrass Zostera noltii (Hemminga et al. 1998), sharing habitats with similar hydrodynamic conditions. Both species are well recognized as ecosystem engineers that reduce hydrodynamic energy from currents (Gambi et al. 1990, Neumeier \& Amos 2006) and waves (Möller et al. 2001, Bouma et al. 2005). The strong reduction of hydrodynamic energy by the stiff $S$. anglica canopies results in strongly enhanced particle accretion within the tussocks, causing $S$. anglica patches to become nutrient rich (Hemminga et al. 1998) and dome shaped (Castellanos et al. 1994, van Hulzen et al. 2007). Reduction of inundation periods following sediment accretion is favourable to S. anglica, which is in essence a terrestrial species, photosynthesising during low tide and taking up nutrients predominantly via its roots (Bouma et al. 2001, 2002 and references therein). In contrast to $S$. anglica, $Z$. noltii is a true marine plant with submerged photosynthesis and nutrient uptake (PérezLloréns \& Niell 1993, Stapel et al. 1996) which uses the water column as its main source for carbon and inorganic nutrients (Touchette \& Burkholder 2000a,b). Although trapping of nutrients via sediment accretion can be advantageous for nutrient supply to $Z$. noltii, too much sediment accumulation would destroy its habitat by increasing the elevation level above its habitat range (Marba \& Duarte 1995, Vermaat et al. 1997). In line with these physiological requirements, sediment accretion can be considered a more favourable modification for $S$. anglica tussocks than for $Z$. noltii meadows.

Understanding the mechanisms by which Spartina anglica and Zostera noltii modify their habitat to different extents is important for the management and conservation of commonly threatened mudflat-salt marsh boundaries. The capacity of $S$. anglica to modify its abiotic habitat is considered to be the key strategy that enables this species to invade many intertidal areas around the world (Bruno 2000, Wang et al. 2006). On mudflats, the habitat modification by $S$. anglica invasion can have a large effect on how the ecosystem functions by causing the displacement, and even the decline, of $Z$. noltii populations (Lacambra et al. 2004). The negative effects of invasive engineers on local populations are not only found for $S$. anglica, but appear to be a general characteristic of such invasive species (reviewed by Crooks 2002), underlining the importance of understanding ecosystem engineering as a growth strategy.

Habitat modification by Spartina anglica and Zostera noltii is related to the reduction of hydrodynamic energy via their shoots. It is, however, not fully understood which organism traits are most important in determining different types of habitat modification. In a previous study, we demonstrated shoot stiffness causes contrasting levels of ecosystem engineering in wave-dominated environments (Bouma et al. 2005). However, tidal currents, rather than waves, dominate many sheltered intertidal mudflat-salt marsh systems. Hence, in the present study we focus on identifying which organism traits are most important for explaining the different capacities for ecosystem engineering between $S$. anglica and $Z$. noltii in flow-dominated intertidal ecosystems. Previous studies have demonstrated that submerged vegetations reduce the flow speed within the canopy (Gambi et al. 1990, Neumeier \& Amos 2006). Such effects have been frequently related to stem or shoot density (Gambi et al. 1990, Nepf 1999). However, other characteristics of the canopy structure such as biomechanical properties also seem to be involved (Nepf 1999).

In the present study we assess the combined effects of biomechanical (i.e. shoot flexibility) and demographic (i.e. shoot density) characteristics on the interaction of submerged plant populations with unidirectional currents to acquire an in-depth understanding of (1) the differences in ecosystem engineering capacity between Spartina anglica and Zostera noltii and (2) the extent to which these differences can be explained by the plant traits, density and flexibility. To achieve our objectives, hydrodynamic parameters were measured within $S$. anglica and $Z$. noltii canopies, as well as on the corresponding models of these species consisting of simplified plant mimics (see 'Materials and methods' for further description). The mimics were useful because their identical morphology and morphometry made it possible to identify which hydrodynamic effects could be attributed to shoot flexibility and/or shoot density. The hydrodynamic variables (current velocity, vertical Reynolds stress and volumetric flow rate of water through the canopy) were selected to enable us to identify which biomechanical and demographic characteristics are most important for explaining patterns of sediment accretion and erosion for these submersed populations. The results are subsequently used to evaluate the role of these biological characteristics in the interactions between seagrass and salt marsh species on intertidal mudflats.

\section{MATERIALS AND METHODS}

Natural and artificial canopies. Hydrodynamic profiles were measured using Spartina anglica and Zostera noltii canopies with different densities (Table 1). To cover the large natural divergences between $S$. anglica and $Z$. noltii densities, mature dense canopies were col- 
lected from the field (high density canopies). Low density canopies (still within the natural range of each species) were obtained by thinning (randomly selected shoots were cut off at the sediment surface) of the high density treatments. Due to practical constraints in providing light during the hydrodynamic measurements, S. anglica and $Z$. noltii plants were illuminated overnight, while the hydrodynamic experiments, which took place during the day, were conducted in darkness. For S. anglica plants, the flume tank was emptied during the light period, whereas for $Z$. noltii plants, it was kept flooded. At the end of the flume measurements, all plants were collected to estimate the number of stems per square meter. On a sub-sample, we also determined the number of leaves per stem and the height of leaf branching. For high density cases, the corresponding measurements were determined by counting sub-samples of the original vegetation.

To get a better understanding of the effects of shoot density and stiffness as variables affecting the hydrodynamic characteristics within submerged canopies, measurements within canopies of simplified plant mimics were also performed. The mimics had contrasting flexibility, but identical dimensions $(0.1 \mathrm{~m}$ long, $0.005 \mathrm{~m}$ wide). We used this proxy to exclude the effects of morphology and morphometry (specifically surface area) when comparing natural submerged canopies of different species. Flexible artificial leaves were constructed by cutting plastic folders into strips, whereas plastic cable ties were used as mimics of Spartina anglica stems. Previous studies showed that these mimics proved to be quite comparable with respect to drag and wave attenuation (Bouma et al. 2005). Both flexible and stiff mimic canopies were constructed at low (615 structures $\mathrm{m}^{-2}$ ) and high (2463 structures $\mathrm{m}^{-2}$ ) densities (Table 1). Given that (1) the high densities typical for Zostera noltii meadows will be much higher than ever found for $S$. anglica and that (2) the width of the mimics was approximately twice

Table 1. Shoot density and canopy height for each experimental treatment. Every experimental treatment included the combination of the vegetation type, shoot density and the free stream velocity

\begin{tabular}{|c|c|c|c|}
\hline \multirow{2}{*}{$\begin{array}{l}\text { Vegetation type, } \\
\text { density treatment }\end{array}$} & \multirow{2}{*}{$\begin{array}{c}\text { Density } \\
\left(\text { structures } \mathrm{m}^{-2} \text { ) }\right.\end{array}$} & \multicolumn{2}{|c|}{ Canopy height (m) } \\
\hline & & $0.05 \mathrm{~m} \mathrm{~s}^{-1}$ & $0.30 \mathrm{~m} \mathrm{~s}^{-1}$ \\
\hline Flexible mimics, low & 615 & 0.100 & 0.050 \\
\hline Flexible mimics, high & 2463 & 0.100 & 0.085 \\
\hline Zostera noltii, low & 4989 & 0.130 & 0.045 \\
\hline Zostera noltii, high & 11565 & 0.130 & 0.045 \\
\hline Stiff mimics, low & 615 & 0.100 & 0.100 \\
\hline Stiff mimics, high & 2463 & 0.100 & 0.100 \\
\hline Spartina anglica, low & 362 & 0.250 & 0.250 \\
\hline Spartina anglica, high & 1396 & 0.250 & 0.250 \\
\hline
\end{tabular}

that of the $Z$. noltii leaves, we chose the high density for the mimics to be approximately half of that of the low density $Z$. noltii vegetation (i.e. 2463 structures $\mathrm{m}^{-2}$; Table 1). This equalled approximately twice the density of the high density Spartina vegetation. The low density mimic bed (i.e. 615 structures $\mathrm{m}^{-2}$ ) is extremely low for $Z$. noltii vegetation, but still within a reasonable density range for Spartina (Table 1). Overall, the selected densities thus represent moderated values in the range covered by natural densities of $S$. anglica and $Z$. noltii (Table 1). Although the choice of these high and low densities for the flexible and stiff mimic canopies remains somewhat arbitrary, it did enable us to compare vegetations of contrasting shoot stiffness for identical densities and dimensions.

Flume tank measurements. The effects of natural and artificial plant populations on hydrodynamic variables were studied in a unidirectional race-track flume tank with $0.4 \mathrm{~m}$ of depth in the water column (Fig. 1; for more details see the description of the Netherlands Institute of Ecology (NIOO) flume in Jonsson et al. (2006). The flume was running at the given speed for at least $10 \mathrm{~min}$ for a stable hydrodynamic regime to develop. Within the flume tank, $x^{-}, y$ - and $z$-axes are respectively oriented to the main flow direction $(x)$, perpendicular to the lateral flume tank walls $(y)$ and vertically $(z)$. Measurements were performed at low $\left(0.045 \mathrm{~m} \mathrm{~s}^{-1}\right)$ and high $\left(0.30 \mathrm{~m} \mathrm{~s}^{-1}\right)$ free stream velocities, respectively. The 3 components of the velocity $(u, v$ and $w)$ were measured at $25 \mathrm{~Hz}$ with an acoustic Doppler velocimeter (ADV, Nortek field version; see Voulgaris \& Trowbridge 1998 for principles of operation). The probe head of the ADV has a small drag surface and the active measuring cell is $5 \mathrm{~cm}$ below the probe head. Both conditions help to minimize the effects of the method in the corresponding measurements. The dimensions of the natural and artificial beds used were $1 \mathrm{~m}$ long $\times 0.6 \mathrm{~m}$ wide, for an area of $0.6 \mathrm{~m}^{2}$. For each canopy, 2 types of measurement designs were performed: (1) a detailed grid measured in the middle of the homogeneous bed ('homogeneous grid'), and (2) a second grid measured at the leading edge of the canopy, designed to study gradients in hydrodynamics ('gradient grid') (Fig. 1).

Homogeneous grid. The homogeneous grid values were measured in a volume of $1.84 \times 10^{-3} \mathrm{~m}^{3}$ at $0.7 \mathrm{~m}$ downstream of the leading edge (see homogeneous grid in Fig. 1). For most canopies, the measuring grid had 1980 points regularly distributed in 11 steps of $0.01 \mathrm{~m}$ in $x, 9$ steps of $0.01 \mathrm{~m}$ in $y$ and 20 steps distributed between 0.01 and $0.24 \mathrm{~m}$ in $z$. For Spartina anglica canopies, the regular grid had 1287 points regularly distributed as previously described for $x$ and $y$, but with 13 steps of $0.02 \mathrm{~m}$ in $z$. In all cases, the ADV took measurements at each point for $5 \mathrm{~s}$, yielding 125 temporal data sets per point (each data set had values 

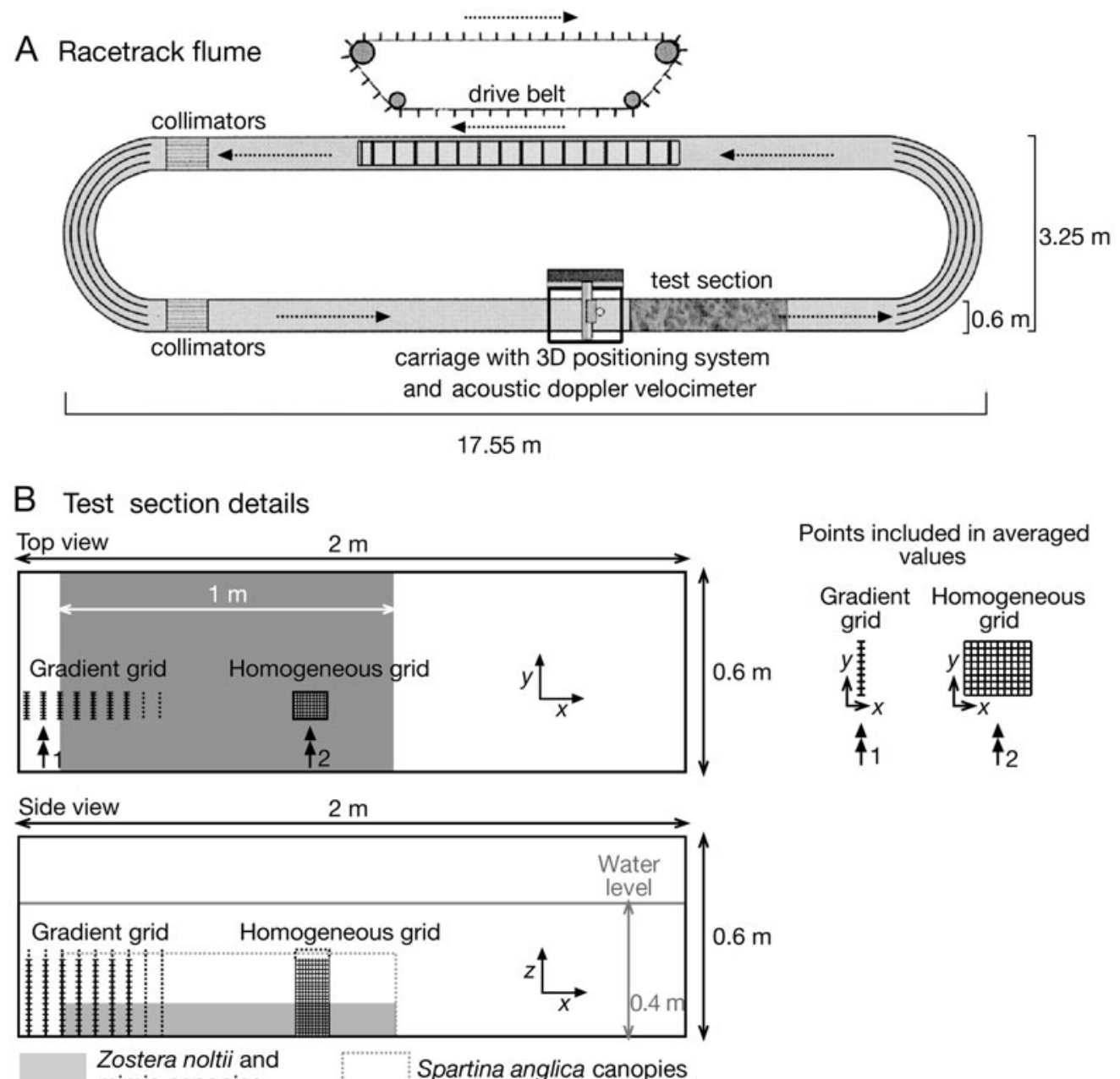

Zostera noltii and
mimic canopies

Spartina anglica canopies

Fig. 1. Schematic diagram of (A) the experimental racetrack flume tank and (B) its corresponding test section. Flow direction is indicated as the $\mathrm{x}$-axis direction. In the test section, the positions of the canopies and the corresponding type of measurements (gradient and homogeneous grids) are shown. The space occupied by canopies is indicated by grey areas. As Spartina anglica had a greater height than the canopies of Zostera noltii and plant mimics, the extra height is indicated by grey dashed lines. Details of the $x-y$ spatially averaged points for both types of grids (i.e. 1: gradient grid with $9 x-y$ averaged points, 2 : 3D grid with $99 x-y$ averaged points) are shown in the top view of (B). The measuring points are in the intersection between the horizontal and vertical lines

of $u, v$ and $w)$. Each vertical profile was constructed by temporally averaging the data from each point (i.e. 125 data sets). Then, to account for horizontal variations in space, the 99 points of the $x-y$ horizontal locations were newly averaged for each $z$-position (see the corresponding scheme of averaged points on Fig. 1B). Results are expressed as profiles of $\langle\bar{u}>$ velocity component (the overbar indicates the temporal averaging on each measurement point and the brackets indicate the spatial averaging in the horizontal plane) and vertical Reynolds stress $\left(\tau_{R}\right)$. See theoretical background section for further details.

Gradient grids at the canopy leading edge. To study the hydrodynamic effects of the plant leading edge, a second type of measuring grid was employed. The gradient grid was not as fine in the $x$ direction as the previous type of grid. The gradient grid was measured within a volume of $5.52 \times 10^{-3} \mathrm{~m}^{3}$ located around the leading edge $\left(8.32 \times 10^{-3} \mathrm{~m}^{3}\right.$ for Spartina anglica $)$. For most cases, the measuring grid had 882 points regularly distributed in 7 steps of $0.05 \mathrm{~m}$ in $\mathrm{x}, 9$ steps of $0.01 \mathrm{~m}$ in $y$ and 14 steps distributed between 0.01 and $0.24 \mathrm{~m}$ in $z$. For $S$. anglica canopies, the gradient grid had 1215 points regularly distributed in 9 steps of $0.05 \mathrm{~m}$ in $x_{1} 9$ steps of $0.01 \mathrm{~m}$ in $y$ and 15 steps distributed between 0.01 and $0.27 \mathrm{~m}$ in $z$. To detect the spatial divergences when moving from outside (i.e. the bare floor) to inside the plant populations (living plant or mimics), the measurements corresponding to each $x$-location were treated as independent vertical velocity profiles (i.e. 7 vertical profiles for most cases, except for $S$. anglica, which had 9 vertical profiles; compare solid and dashed black lines, respectively, in 
top and side views of Fig. 1B). At each point of the gradient grid, the ADV made measurements for $20 \mathrm{~s}$, yielding 500 temporal data sets per point (each data set had values of $u, v$ and $w$ ). Each vertical profile was constructed by temporally averaging the data from each point (i.e. 500 data sets) and spatially averaging for each $x$-position and each $z$-position the 9 points of the $y$-locations (see the corresponding scheme of averaged points on Fig. 1B). The vertical profiles included 2 profiles over bare floor in front of the plants (at 0.10 and $0.05 \mathrm{~m}$ before the leading edge, respectively), 5 measurements in and above the canopies (at 0, 0.05, 0.10, 0.15 and $0.20 \mathrm{~m}$ from the leading edge, respectively) and 2 extra measurements within the populations of $S$. anglica $(0.25$ and $0.30 \mathrm{~m}$, represented as dashed black lines on Fig. 1B). At each $x$-location, the height of the corresponding canopy was recorded.

Statistical analyses. Spatially averaged (99 measurements in the $x-y$ plane for the homogeneous grid and 9 in the $y$-plane for the gradient grid) flow velocity $(<\bar{u}>)$ and vertical Reynolds stress $\left(\tau_{R}\right)$ at each depth $(z)$ interval are graphically represented with their respective $95 \%$ confidence intervals (CI). Differences in $\langle\bar{u}>$ were considered significant $(\mathrm{p}<0.05)$ if the $95 \% \mathrm{CI}$ did not overlap (cf. Schenker \& Gentleman 2001). Detailed statistical comparisons of $\left(\tau_{R}\right)$ near the sediment surface $(z$ $=0.02 \mathrm{~m}$ ) measured in the homogeneous grids (i.e. approximately 99 measurements in the $x-y$ plane) were conducted using 1-way ANOVA. Post hoc Tukey's unequal N HSD test was used to determine significant differences between group means within the ANOVA setting. The difference/effect was considered significant at the $\mathrm{p}<0.05$ level. In nearly all statistical comparisons the variances of $\left(\tau_{R}\right)$ at each depth interval were found to be heterogeneous (and transformations of the data did improve this problem). However, as the sample size of each mean value was 'relatively large' and the experimental design 'relatively balanced' the validity of the test and the probabilities associated with the F-ratio distribution are not affected much by violations of this assumption (Underwood 1997, p 192). Regression lines and their corresponding coefficients $\left(\mathrm{r}^{2}\right)$ were calculated for canopy volumetric flow rate (\%) versus canopy velocity reduction (\%) for use in Fig. 5.

A brief theoretical background. To evaluate the effects of shoot flexibility and shoot density of submerged plant populations on the corresponding effects on the local hydrodynamics, we determined the following hydrodynamic variables: (1) $<\bar{u}>$ profiles, which show the canopy's capacity for modifying current velocity, (2) vertical Reynolds stress $\left(\tau_{R}\right)$ near the bed, which provides information on the erosive forces, and (3) the volumetric flow rate crossing the canopy $\left(Q_{C}\right)$, which is used as a proxy for the capacity to increase sediment accretion, since this variable quantifies the volume of water (where the sediment particles are suspended) that actively crosses through the plants and, therefore, indirectly quantifies the magnitude of the number of particles affected by the velocity reduction. The combination of these variables accurately describes the effects of submerged plant populations on the local hydrodynamics and provides the most relevant information to understand associated feedback effects.

ADVs provide detailed information on the 3 velocity components separately $(u, v, w)$ as described in Eqs. (1) through (3):

$$
\begin{gathered}
\mathrm{u}=\bar{u}+u \\
\mathrm{v}=\bar{v}+v^{\prime} \\
\mathrm{w}=\bar{W}+w^{\prime}
\end{gathered}
$$

These components allow the estimation of the vertical Reynolds stress for each individual point $\left(\tau_{R_{i}}\right)$ :

$$
\tau_{R_{i}}=-\rho \overline{u^{\prime} W^{\prime}}
$$

And subsequently the average Reynolds stress for the given surface area $\left(\tau_{R}\right)$ is:

$$
\tau_{R}=\left\langle-\rho \overline{u^{\prime} W^{\prime}}\right\rangle
$$

where $\tau_{R}=$ vertical Reynolds stress $(\mathrm{Pa}), u^{\prime}, v^{\prime}$, and $w^{\prime}$ are the fluctuations from the averaged value of the 3 velocity components, respectively, and $\rho=$ seawater density $\left(1025 \mathrm{~kg} \mathrm{~m}^{-3}\right)$. The sign of $\tau_{R}$ indicates the direction of the momentum transfer (i.e. positive values imply momentum transfer towards the bed and vice versa). In the present study, $\tau_{R}$ was calculated at $0.02 \mathrm{~m}$ from the sediment-water interface and used to evaluate the generation or attenuation of erosive forces by comparison with bare areas.

Finally, the velocity gradients were used to calculate the volumetric flow rate crossing the canopy $\left(Q_{C}\right)$ and the velocity reduction within the canopy (\% $\left.U_{\text {reduction }}\right)$. For this study, $Q_{C}$ was expressed as percent of the flume tank volumetric flow rate $\left(Q_{C \%}\right)$ according to Eqs. (5) through (8):

$$
\begin{gathered}
Q_{C \%}=\frac{Q_{C}}{Q_{T}} \cdot 100 \\
Q_{C}=\sum_{0}^{h_{C}} Q_{i} \\
Q_{T}=\sum_{0}^{h_{W}} Q_{i} \\
Q_{i}=y \times\left(z_{i}-z_{i-1}\right) \times \bar{u}_{z_{i}}
\end{gathered}
$$

where:

$Q_{C \%}=$ canopy volumetric flow rate $(\%) ; Q_{C}=$ canopy volumetric flow rate $\left(\mathrm{m}^{3} \mathrm{~s}^{-1}\right) ; Q_{T}=$ flume tank volumetric flow rate $\left(\mathrm{m}^{3} \mathrm{~s}^{-1}\right) ; h_{C}=$ canopy height $(\mathrm{m})$; $h_{W}=$ water column height $(0.40 \mathrm{~m}) ; Q_{i}=$ volumetric 
flow rate through the layer $\left(z_{i} \times z_{i-1}\right) \times y_{i} y=$ width of the flume tank $(0.60 \mathrm{~m}) ; \bar{u}_{z_{i}}=$ averaged $u$ component of the velocity at depth $z_{i}$.

The canopy velocity reduction ( $\left.\% U_{\text {reduction}}\right)$ was also expressed as percentage and calculated according to Eq. (9):

$$
\% U_{\text {reduction }}=\frac{\bar{u}_{C, \text { control }}-\bar{u}_{C, \text { treatment }}}{\bar{u}_{C, \text { control }}} \times 100
$$

canopies is predominantly affected by shoot density rather than by shoot flexibility. That is, the stiff and flexible mimics with the same density had comparable current velocities within their canopy, whereas large significant differences were found for identical mimics with contrasting densities (Fig. 2A-D). However, flexibility strongly affected the height of the canopy at high velocity, and, thus, the volume occupied by the plants. where $\bar{u}_{C \text {, treatment }}=$ averaged value of $\bar{u}$ within the canopy height $\left(h_{C}\right)$, and $\bar{u}_{C \text {, control }}$ = averaged value of $\bar{u}$ at the bare bed, but within the water layer with the same height as $h_{C}$.

\section{RESULTS}

\section{Canopy reconfiguration}

A primary and important difference between flexible and stiff plants (both living and mimics) is the pronounced capacity for reconfiguration (i.e. streamlining by bending) of the flexible canopies at high velocity. Such reconfiguration is negligible in stiff plants. In still water $\left(0 \mathrm{~m} \mathrm{~s}^{-1}\right)$, the canopy height was $0.10 \mathrm{~m}$ for artificial meadows, $0.13 \mathrm{~m}$ for Zostera noltii and $0.25 \mathrm{~m}$ for Spartina anglica (Table 1). The height remained similar at a low velocity $\left(0.045 \mathrm{~m} \mathrm{~s}^{-1}\right)$. However, at high velocity $\left(0.30 \mathrm{~m} \mathrm{~s}^{-1}\right)$ both living and mimic flexible canopies were considerably deflected (Table 1), reducing the canopy volume in most cases by more than $50 \%$.

\section{Velocity profiles}

Living and mimic populations significantly affected the vertical velocity profile when compared with the bare floor ( $p<$ 0.05, $95 \%$ CI of measurements with plant canopies rarely overlapping those of the control, Fig. 2). While the bare bed exhibited a typical logarithmic $<\bar{u}>$-profile (solid line, Fig. 2), in most cases relatively homogeneous $\langle\bar{u}>$ values were observed within the plant canopies, with values clearly reduced with respect to the bare sediment, and velocities accelerated above the canopy.

The use of mimics demonstrated that velocity attenuation within the submerged

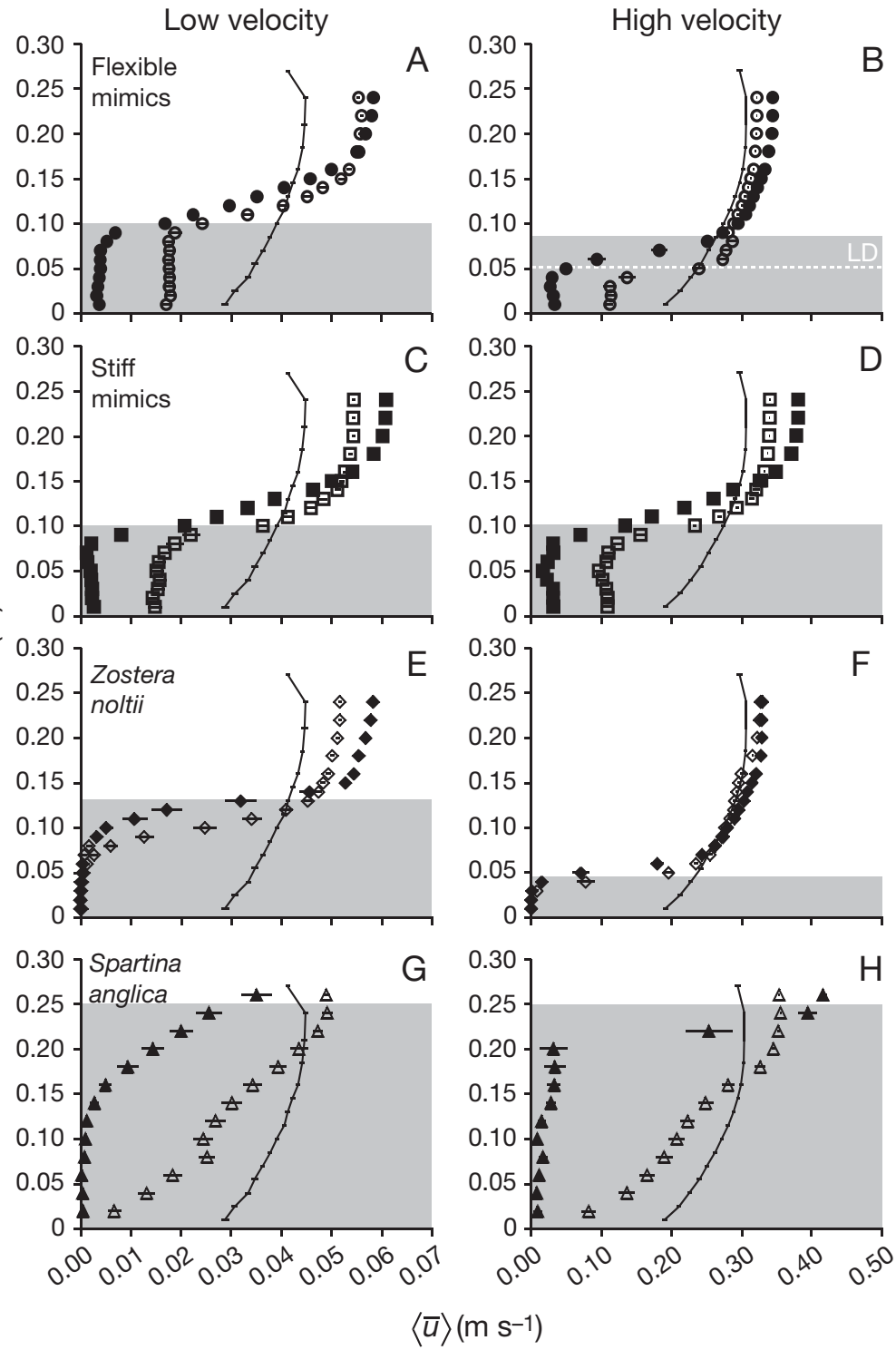

Fig. 2. Vertical profiles of $\langle\bar{u}>$ velocity component at $0.70 \mathrm{~m}$ within the artificial and natural canopies at low and high free stream velocities. (A \& B) Flexible mimic beds, (C \& D) stiff mimic beds, (E \& F) Zostera noltii meadows, (G \& H) Spartina anglica tussocks. Open symbols represent low density vegetations and closed symbols represent high density vegetation (see Table 1 for corresponding densities). On each figure, the $\bar{u}$-profile corresponding to the bare floor is represented as a black line. The grey area represents the corresponding canopy height. In (B), the white dashed line within the grey area represents the canopy height at low density. Error bars correspond to the $95 \% \mathrm{CI}$ 
As a result, flexibility strongly affected the volume above the canopy and thereby the magnitude of water acceleration above the canopy (see Fig. 2B,D).

The effects of shoot density demonstrated with mimic canopies explain the strong velocity reduction observed within the 2 densities of Zostera noltii canopies (see Fig. 2E,F). In the opposite situation, the effects associated with shoot density could also partly explain the linear $\langle\bar{u}>$ increase observed within the low density Spartina anglica canopy (Fig. 2G,H). However, in this particular case, differences in canopy height probably played a major role, since the long and stiff stems of $S$. anglica occupied approximately $60 \%$ of the entire water column, forcing the water to cross through the canopy instead of establishing a skimming flow.

\section{Vertical Reynolds stress $\left(\tau_{R}\right)$}

The vertical Reynolds stress $\left(\tau_{R}\right)$ (Fig. 3) was estimated at $0.02 \mathrm{~m}$ from the sediment-water interface to evaluate the influence of unidirectional currents on sediment stability within vegetated beds. $\tau_{R}$ was significantly affected by the presence of mimic canopies at low (1-way ANOVA, $F_{4,424}=52.5, \mathrm{p}<0.005$, Fig. 3A) and high (1way ANOVA, $F_{4,424}=96.54, \mathrm{p}<0.005$, Fig. 3B) velocities.
Post hoc examination revealed that at both velocities high density flexible mimic canopies significantly reduced $\tau_{R}$ values when compared with both stiff mimics and bare areas (post hoc Tukey's unequal N HSD test, $\mathrm{p}<0.05$, Fig. 3A,B). At high velocity this effect became more pronounced, resulting in significant reduction in $\tau_{R}$ within the low density canopy also ( $p<0.05$, Fig. 3B). The influence of stiff canopies on $\tau_{R}$ was more complicated than for flexible vegetation, as the effect depended upon current velocity. At low velocity, the 2 stiff mimic canopies had $\tau_{R}$ values significantly higher than the bare floor ( $p<0.05$, Fig. 3A). At high velocity the stiff mimic canopies (both densities) had $\tau_{R}$ values significantly lower than those for the bare floor ( $p<0.05$, Fig. 3B), although they were only significantly higher than the flexible mimic canopies at high density $(p<0.05$, Fig. 3B).

Also, $\tau_{R}$ was significantly affected by the presence of natural canopies at low (1-way ANOVA, $F_{4,407}=13.7$, $\mathrm{p}<0.001$, Fig. 3C) and high (1-way ANOVA, $F_{4,410}=$ 359, $\mathrm{p}<0.005$, Fig. 3D) velocities. Post hoc examination revealed that in all the treatments investigated, natural plant canopies significantly reduced $\tau_{R}$ values when compared with measurements above bare sediment. At low density, significant differences were detected only between the low density Spartina anglica popu-
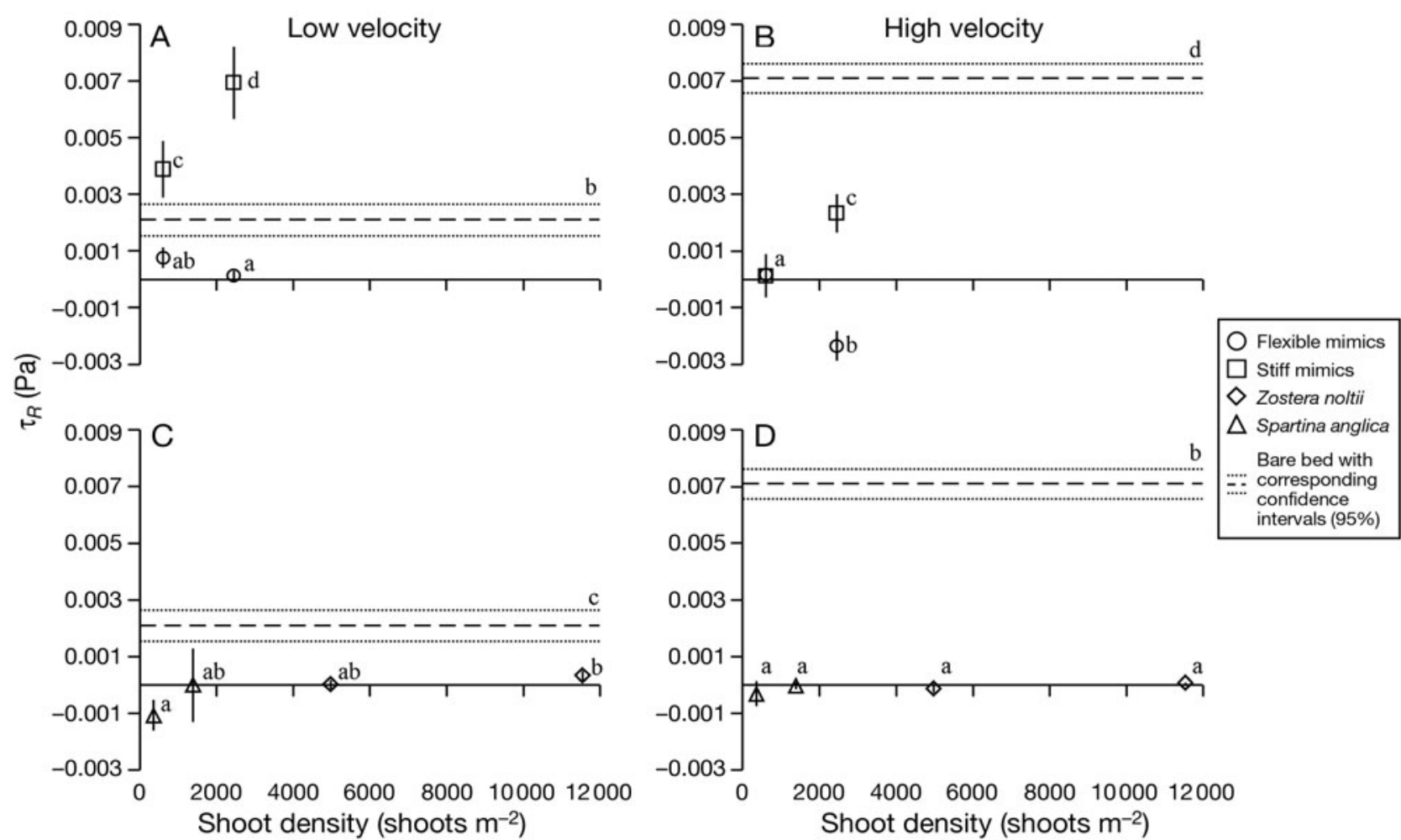

Fig. 3. Effects of submersed vegetation on the vertical Reynolds stress $\left(\tau_{R}, \mathrm{~Pa}\right)$ in the first $0.02 \mathrm{~m}$ of the water column versus shoot density at low and high free stream velocities. (A,B) mimic canopies; (C,D) natural canopies of Zostera noltii and Spartina anglica. Dashed lines represent bare bed $\tau_{R}$ averaged values, and corresponding $95 \%$ CI. Error bars correspond to the $95 \%$ CI. Lower case letters inside the graphs refer to significantly different groups as indicated by the post hoc analysis 
lation and the high density population of Zostera noltii ( $p<0.05$, Fig. 3C). At high velocity, the presence of plants had the same effect for each species at both densities (post hoc Tukey's unequal N HSD test, p $<0.05$, Fig. 3D). The morphological and morphometric differences between the stiff mimic and $S$. anglica canopies were much larger than those between the flexible mimic and Z. noltii. Therefore, it was not surprising that the $\tau_{R}$ pattern described at low velocity also diverged qualitatively between the stiff mimic and $S$. anglica canopies.

\section{Canopy volumetric flow rate}

The volumetric flow rate of water through the canopy $\left(Q_{C}\right)$ was calculated by combining velocity profiles measured within the canopy with the height occupied by the plants, thus providing an indication of the rate of sediment supply within the population. To account for slight variations in experimental velocity treatments and facilitate comparisons between plant types, $Q_{C}$ was further normalised to the total flow rate of water passing through the entire flume section and thus, expressed as a percentage $\left(Q_{C \%}\right)$. Thus, horizontal gradients in both vertical velocity profiles and/or canopy height combine to determine the corresponding horizontal gradients in $Q_{C \%}$ (Fig. 4).

The results using mimics (with identical dimensions) show that in non-deflected populations (i.e. stiff and flexible mimics at low velocity) shoot density decreased mean water velocity within the canopy and $Q_{C \%}$ (Fig. 4). Thus, the magnitude of the spatial changes in $Q_{C \%}$, and canopy velocity, were solely dependent upon the shoot density, resulting in a similar pattern at both densities. The role of shoot density is, however, not so clear for deflected canopies, as the spatial pattern of $Q_{C \%}$ and mean canopy velocity may diverge at increasing distances from the leading edge as a consequence of spatial changes in canopy height (i.e. spatial changes in canopy deflection; see flexible mimics in Fig. 4B). When the canopy deflection is spatially constant (see low density flexible mimics in Fig. 4B), the effects of shoot density on canopy velocity and $Q_{C \%}$ are similar to those described for non-deflected canopies. However, when the canopy height increases with distance from the leading edge (i.e. there are spatial changes in canopy deflection; see high density flexible mimics in Fig. $4 \mathrm{~B}), Q_{C \%}$ increases downstream, instead of showing a consistent decrease, as observed for non-deflected vegetation. In some cases, $Q_{C \%}$ within the canopy was larger in the high shoot density treatment than in the low density one (see flexible mimics in Fig. 4B), showing that spatial divergences in canopy height can be even more relevant than shoot density in determining $Q_{C \%}$.
The pattern observed for mimics provides a basis to satisfactorily understand the more complex patterns observed in Spartina anglica and Zostera noltii. Quantitative differences observed between natural and mimic vegetations can be attributed to differences in shoot length and/or level of flexibility. In contrast to the mimics, the living $Z$. noltii showed virtually no differences between the high and the low densities. This was almost certainly due to the extremely high shoot density of the natural $Z$. noltii canopies used, even in the 'low density' treatment. For this small seagrass, the maximum attenuation of velocity was observed at $0.7 \mathrm{~m}$ from the leading edge (Fig. 2E,F). This, together with the small differences in velocity within the canopy observed between high and low density at the leading edge, suggests that the $Z$. noltii densities used in this study had reached their maximum capacity for velocity attenuation. In addition to being efficient at reducing velocity within the canopy (Fig. 2E,F), Z. noltii also readily bends (i.e. $Z$. noltii canopies deflect even at $0.045 \mathrm{~m} \mathrm{~s}^{-1}$ Fig. 4A). At low velocity, the $Z$. noltii canopies exhibited a gradual increase in height with increasing distance downstream that, together with the canopy velocity spatial pattern, explained the horizontal increase in $Q_{C \%}$, instead of the expected decrease. At high velocity, the deflection of $Z$. noltii shoots was at its maximum, forcing the canopy height to be constant and leading to a decrease in $Q_{C \%}$ downstream.

In contrast to Zostera noltii shoots, those of Spartina anglica were resistant to bending. Both at low and high velocities, $S$. anglica showed a negative effect of shoot density on the canopy volumetric flow rate, which became more pronounced with increasing distances downstream (Fig. 4). However, S. anglica also had extremely high values of $Q_{C \%}$, when compared with mimics or $Z$. noltii (note difference in scale for $Q_{C \%}$ in $S$. anglica). This is a consequence of the long and stiff stems of this species, which occupied approximately $60 \%$ of the water column, forcing the water to cross through the canopy instead of establishing a skimming flow.

\section{Implications for ecosystem engineering capacity by combining $\boldsymbol{Q}_{C \%}$ and $\% U_{\text {reduction }}$}

The effects of shoot density and stiffness on the potential for sediment accretion of each species are summarized by plotting $Q_{C \%}$ against the percent reduction in mean velocity within the canopy relative to the control $\left(\% U_{\text {reduction }}\right)$ during the highest velocity treatment (Fig. 5), when flexible canopies are deflected and stiff ones remain upright. A large potential for sediment accretion within a submerged plant canopy is related to a high $Q_{C \%}$ (i.e. a high sediment supply), moderate to strong velocity reduction within the canopy (i.e. high 


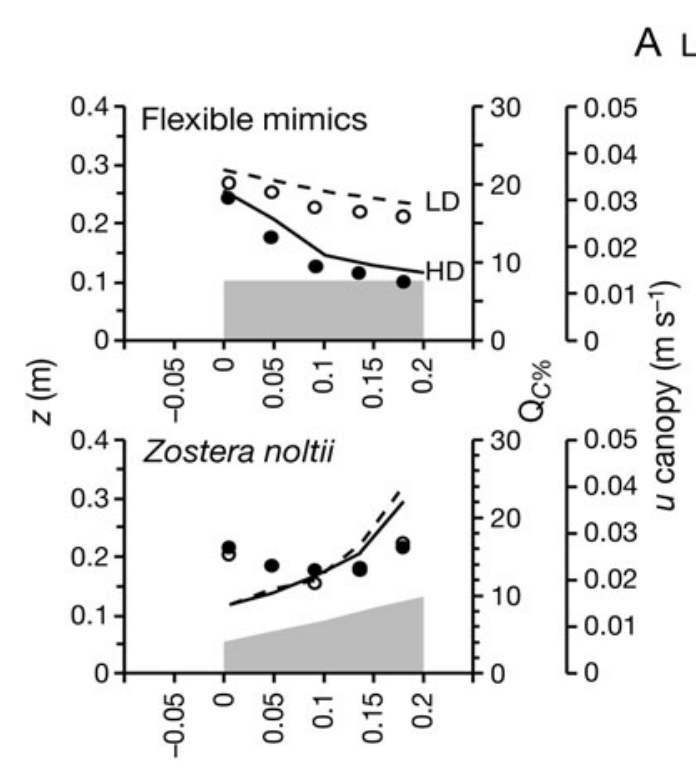

A Low velocity $\quad-0$ High density
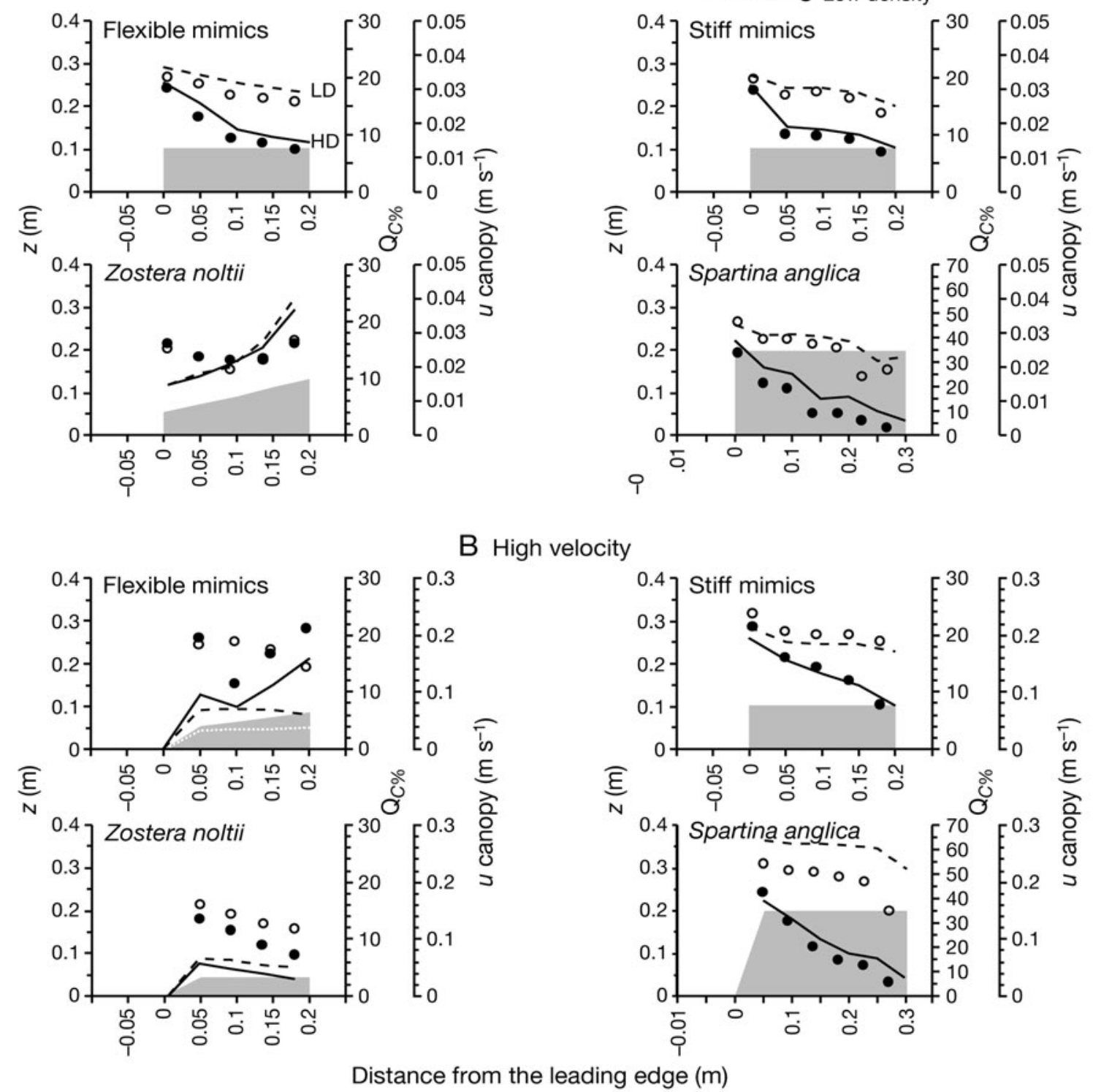

Fig. 4. Canopy volumetric flow rate $\left(Q_{C \%}\right.$, solid and dashed lines), average velocity within the canopy $(u$ canopy, $\bullet$ and $O)$ and the corresponding canopy height (grey areas) of experimental treatments at (A) low and (B) high free stream velocities. On the graph corresponding to high velocity and flexible mimic canopies, the white dashed line within the grey area represents the canopy height at low density. Note the change of scale for volumetric flow rate crossing Spartina anglica tussocks

sediment retention) and relatively low values of nearbed $\tau_{R}$. We know that, at high velocity, near-bed $\tau_{R}$ was small, when compared with that for bare sediment, within all the submersed populations examined (i.e. living and mimic canopies Fig. 3B,D). An increase in shoot density increases velocity reduction within the canopy, but also decreases $Q_{C} \%$ (Fig. 5). This negative relation between $Q_{C} \%$ and velocity reduction limits the capacity of a canopy to favour sediment accretion at very high shoot densities, when the unidirectional flow is essen- tially relocated over both flexible and stiff canopies (i.e. skimming flow is favoured and $Q_{C \%}$ approaches zero, see bottom right side of Fig. 5). However, at moderate shoot densities, when the velocity reduction still allows a reasonably high mean velocity within the canopy, the role of shoot stiffness in determining the potential for sediment accretion became evident. For densities with similar values of velocity reduction, flexible plants had strongly reduced $Q_{C \%}$. This reduction was a consequence of the velocity and density dependent deflec- 


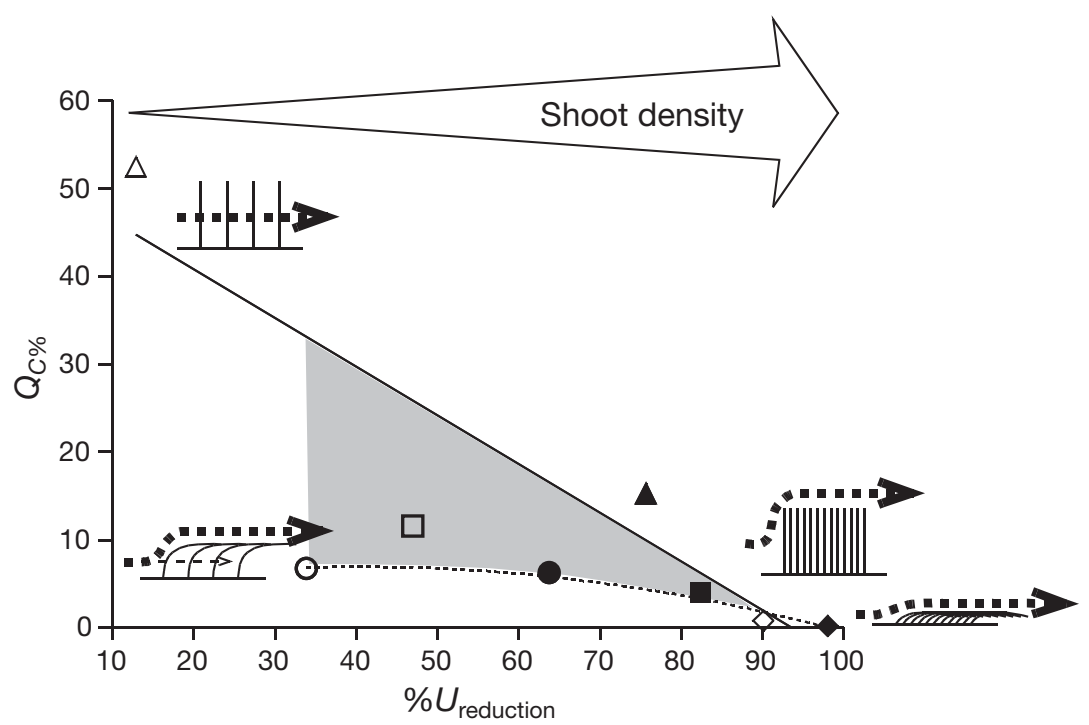

Fig. 5. Canopy volumetric flow rate $\left(Q_{C \%}\right)$ versus percentage of velocity reduction within the canopies $\left(\% U_{\text {reduction }}\right)$ at $0.3 \mathrm{~m} \mathrm{~s}^{-1}$ free stream velocity. Circles and squares represent flexible and stiff mimics, respectively. Diamonds and triangles represent Zostera noltii and Spartina anglica populations, respectively. Open symbols represent low density canopies; solid symbols represent high density ones (see Table 1 for shoot density values). Small schematic diagrams illustrate the behaviour of shoots and flow on extreme cases for stiff and flexible vegetations. Correlation lines for stiff (solid line: $Y=52.6 \times 0.56 X, \mathrm{r}^{2}=0.822$ ) and flexible cases (dashed line: $Y=3.45+0.17 X \times$ $\left.0.002 X^{2}, r^{2}=0.968\right)$ are represented. The grey area between the correlation lines represents the reduction in volumetric flow rate associated with the bending of the canopy of flexible plants tion of the flexible canopy. The grey area highlighted in Fig. 5 indicates the magnitude of the reduction in $Q_{C \%}$ associated with plant bending.

\section{DISCUSSION}

The results of this study highlight the main differences in habitat modification between 2 key species (Zostera noltii meadows and Spartina anglica tussocks) occurring in soft sediment pioneer areas of European Atlantic tidal salt marshes. Whereas we previously focussed on wave-dominated habitats (Bouma et al. 2005), we now explain why the stiff stems of $S$. anglica are also efficient in promoting sediment accretion within its tussocks in flow-dominated environments. Spartina anglica is able to reduce current velocity, which is important for sediment accretion, whilst simultaneously allowing a relatively high volumetric flow rate through its undeflected canopies, thus providing a source for sediment accretion. Upon exposure to currents, the bending of the flexible shoots of $Z$. noltii is an effective mechanism to prevent bed floor erosion by efficiently reducing $\tau_{R}$, but without increasing the chance for habitat burial as sediment is deflected with the current above the meadow. To our knowledge, the present work is the first to highlight the importance of volumetric flow rate when examining the hydrodynamic effects of submerged benthic macrophytes; previous studies mainly focus on $\langle\bar{u}\rangle$, turbulent kinetic energy (TKE) and $\tau_{R}$. In the next sections, we discuss in depth the ecosystem engineering characteristics of these submerged plant populations from a mechanistic point of view. The importance of the corresponding feedbacks is addressed in order to enhance our understanding of the co-occurrence of these marine and terrestrial species on intertidal mudflats.

\section{Role of density and flexibility in the hydrodynamic properties of vegetated benthos}

Enhanced sediment accretion and/or reduced erosion associated with water velocity reduction are key factors in the modification of coastal habitats. Numerous studies have previously demonstrated that submerged plants modify their habitat via reduction of water velocity within their canopies (Gambi et al. 1990, Koch 1996, Widdows \& Brinsley 2002, Neumeier \& Ciavola 2004). The present work carries this one step further by discriminating between the particular hydrodynamic effects of the density and flexibility of shoots, which directly affect sediment accretion and erosion.

The present work agrees with previous studies regarding the positive effects that shoot density has on the capacity of submerged plants to attenuate current velocity (Fonseca et al. 1982, Gambi et al. 1990, Nepf 1999, Neumeier \& Ciavola 2004). However, this effect reaches a limit when water velocity is completely attenuated within the canopy, explaining the marginal differences between the 2 relatively high Zostera noltii densities studied here. Widdows \& Brinsley (2002) also described the existence of such a limit for Spartina anglica by reporting a threshold of 400 stems $\mathrm{m}^{-2}$ for a $75 \%$ velocity reduction within $S$. anglica populations. Once maximum velocity attenuation is reached, the velocity within the canopy becomes almost zero, while a skimming flow develops above the canopy.

Literature data and results from this study using mimics and natural canopies suggest that shoot density is an excellent proxy to determine differences in the capacity for water velocity attenuation, provided that the populations being compared (1) are not extremely dense, (2) have a comparable shoot size and (3) have comparable stiffness. However, shoot density is not 
very useful for explaining differences in attenuation of current velocity for species that typically develop high density populations, like temperate small seagrasses such as Zostera noltii (Brun et al. 2003, Peralta et al. 2005). Shoot density should also not be considered a good proxy to determine differences in current velocity within canopies with strongly dissimilar shoot morphology, as changes in the projected surface due to morphological differences can be associated with divergences in the drag forces and the corresponding capacity for velocity reduction (Denny 1988, Vogel 1994).

Shoot flexibility clearly modifies the effects associated with shoot density by spatial reconfiguration of the canopy through bending (i.e. by altering the spatial pattern in canopy height). On the one hand, canopy deflection may increase the density of bent leaves at the top of the canopy, increasing the chance for the establishment of skimming flow (Neumeier \& Amos 2006). On the other hand, the spatial differences in canopy height alter $Q_{C} \%$ and canopy velocity, which may increase, not decrease, with distance from the leading edge.

\section{Interpreting the consequences of flexibility and density for sediment dynamics}

The effects of shoot density and flexibility on velocity profiles may also affect the capacity of the submersed plant populations to favour sediment deposition. Sediment accretion associated with vegetated areas generally requires the combination of 3 conditions: (1) a sufficient load of material suspended in the water column, (2) sufficient flow of water to carry the sediment load through the canopy and (3) a reduction in water velocity within the canopy (and low $\tau_{R}$ to ensure no resuspension) to enhance accretion of the supplied sediment. Assuming (1) to be present, concluding (3) to be true based on both present results as well as those from published literature, and excluding extremely sparse vegetation that enhances turbulence (Bouma et al. 2007), our results suggest that the capacity for trapping sediment by submerged plant populations is positively influenced by the volumetric flow rate crossing the canopy. The present study clearly shows that $Q_{C \%}$ strongly depends on canopy height (i.e. depends on shoot length and/or shoot flexibility) and on the mean velocity within the canopy (i.e. depends on shoot density) (Hendriks et al. 2008).

Canopy height is determined by shoot length for stiff plants (Nepf \& Vivoni 2000), and by a set of mechanical properties that determine the resistance against bending in flexible ones. The resistance against bending can be estimated by calculating the overall flexural stiffness of a shoot, by multiplying the second moment of area $(I$, measure of how the biomass is distributed within the stem, $\left.\mathrm{m}^{4}\right)$ with the elasticity modulus $(E$, measure for the resistance of material to deformation, $\mathrm{N} \mathrm{m}^{-2}$ ) (Wainwright et al. 1976). A few simple measurements show that the second moment of area for Spartina anglica and Zostera noltii is around $3 \times 10^{-11}$ and $1 \times 10^{-15}$, respectively (Bouma et al. 2005). This implies that even if both species were constructed from material with a similar resistance to deformation (i.e. similar $E$ ), the overall flexural stiffness will be much larger in $S$. anglica than in $Z$. noltii due to the shape of the structures. In our study we saw that even though the shoot length was longer for $Z$. noltii than for the flexible mimics, the canopy height was lower, indicating that $Z$. noltii was more flexible than the flexible mimic (Fig. 4).

In agreement with previous studies, this work suggests that flexibility plays a major role in the capacity that submerged canopies have to trap sediment (Koch 2001, Clarke 2002, Gacia et al. 2003). As plants bend the volumetric flow rate crossing the canopy is reduced (Fig. 5), which explains previous observations describing the lack of significant sedimentation in small seagrass populations, or the reduction in flow rate when compared with larger species (Heiss et al. 2000, Mellors et al. 2002). Submerged flexible canopies do, however, protect the coastal bed by reducing friction forces near the water-sediment interface (i.e. vertical Reynolds stress), thus, directly protecting the bed from erosive processes at both high and low velocities.

\section{Benefits of ecosystem engineering: hydrodynamic feedbacks for submerged vegetations}

Despite the numerous physiological and biomechanical differences between Spartina anglica and Zostera noltii, both species can coexist on intertidal mudflats. In this transitional terrestrial-marine area, S. anglica depends upon trapping sediments and seston to expand its habitat (Castellanos et al. 1994, Hemminga et al. 1998, van Hulzen et al. 2007). Our present study on unidirectional currents is in agreement with our previous studies on waves (Bouma et al. 2005), suggesting that the capacity of $S$. anglica for trapping particles (i.e. sediment and seston) is positively controlled by the density of stems, which determines the efficiency of velocity reduction within the nondeflected canopy at high water velocity. Similar to that of $S$. anglica, the success of seagrasses also depends on acquiring resources and avoiding stresses (Koch 2001). In the intertidal zone, seagrass populations may benefit from high supplies of resources (i.e. light, carbon and nutrients), but have to cope with important stresses, such as emersion periods, hydrodynamic 
forces and burial by sediment (Marba et al. 1994, Vermaat et al. 1997, van Katwijk et al. 2000, Peralta et al. 2005). Thus, it is not surprising that temperate seagrasses that typically succeed on intertidal mudflats are small and fast growing species, which tend to form dense populations (Heiss et al. 2000, van Katwijk et al. 2000, Peralta et al. 2005). Together with the resistance to desiccation associated with small and dense seagrass populations (Hemminga \& Duarte 2000), the present results support the hypothesis that the biomechanical (i.e. shoot flexibility) and demographic (i.e. shoot density) characteristics of these small species help them to cope with the physical stresses of intertidal areas and efficiently protect their habitat. With flexible, short and dense canopies, intertidal seagrass populations may (1) have access to the water column resources by flapping the leaves within the mixing layer formed at the top of the canopy (Ghisalberti \& Nepf 2002), (2) protect the habitat from sedimentation by keeping a low canopy volumetric flow rate (Fig. 4) and (3) protect the habitat from erosion by efficiently reducing the stresses near the bottom floor (Fig. 3).

Besides the autoecology of these species, the ecological consequences of the existence of adjacent habitats are also important. The presence of small seagrasses occurring in high intertidal areas, such as Zostera noltii, may provide the initial sediment stabilization necessary for the establishment of saltmarsh pioneer species (Langlois et al. 2003). Similar to previous descriptions of extreme ecosystems, the protection of seagrass canopies may 'facilitate' the settlement of $S$. anglica seedlings in the littoral zone by preventing their detachment during tidal movements (Bruno 2000). The high productivity associated with seagrass communities must supply an important source of seston for the development of adjacent $S$. anglica tussocks (Hemminga et al. 1998). Once S. anglica is established, sediment trapping, as explained by this study, will allow lateral expansion. This may eventually result in this species taking over of the habitat of the more sedimentary neutral seagrass. The inherent difference in how $Z$. noltii and $S$. anglica affect hydrodynamics by their contrasting shoot stiffness, thus explains why $S$. anglica is able to trap more sediment and thereby invade and occupy $Z$. noltii habitats with important consequences for ecosystem functioning.

\section{CONCLUSIONS}

This work identifies shoot density and, particularly, flexibility as important variables in determining the physical functions of submerged plant populations in relation to sediment accretion and bed stability of intertidal areas. In general terms, it can be concluded that stiff canopies have a larger capacity to trap sediment than do flexible ones by combining velocity reduction with a large supply of sediment, which is provided by the volumetric flow of water crossing the canopy. On the other hand flexible plants are most efficient at reducing stresses near the bottom via a reconfiguration of their leaves. Shoot density increases the magnitude of these effects when density values are moderate. However, once the maximum velocity attenuation is reached, submerged canopies seem to essentially affect the water flow as if they were solid obstacles, resulting in a substantial relocation of the water flow above the canopy (i.e. skimming flow is favoured).

Acknowledgements. This work was supported by a Marie Curie fellowship (EU contract EVK3-CT-2001-50006) and the Spanish national project (EVAMARIA, CTM2005-00395/ MAR). E.P.M. was supported by a Marie Curie host fellowship for transfer of knowledge (EU MTKD-CT-2004-509254). We thank Jos van Soelen, Bas Koutstaal and Lowie Haazen for invaluable technical assistance. We thank also the 3 anonymous reviewers for their valuable comments that greatly improved this manuscript. This is publication 4338 of Netherlands Institute of Ecology (NIOO-KNAW).

\section{LITERATURE CITED}

Bouma TJ, Nielsen KL, Van Hal J, Koutstaal B (2001) Root system topology and diameter distribution of species from habitats differing in inundation frequency. Funct Ecol 15: 360-369

Bouma TJ, Stapel J, van der Heiden J, Koutstaal B, van Soelen J, van Ijzerloo L (2002) Relative importance of macrophyte leaves for nitrogen uptake from flood water in tidal salt marshes. Mar Ecol Prog Ser 240:93-104

> Bouma TJ, De Vries MB, Low E, Peralta G, Tanczos IC, Van De Koppel J, Herman PMJ (2005) Trade-offs related to ecosystem-engineering: a case study on stiffness of emerging macrophytes. Ecology 86:2187-2199

Bouma TJ, Van Duren LA, Temmerman S, Claverie T, BlancoGarcia A, Ysebaert T, Herman PMJ (2007) Spatial sedimentation patterns within patches of epibenthic structures: combining field, flume and modelling experiments. Cont Shelf Res 27:1020-1045

Brun FG, Pérez-Lloréns JL, Hernández I, Vergara JJ (2003) Patch distribution within-patch dynamics of the seagrass Zostera noltii Hornem. at los Toruños salt-marsh (Cádiz Bay, Natural Park, Spain). Bot Mar 46:513-524

Bruno JF (2000) Facilitation of cobble beach plant communities through habitat modification by Spartina alterniflora. Ecology 81:1179-1192

> Castellanos EM, Figueroa ME, Davy AJ (1994) Nucleation and facilitation in saltmarsh succession: interactions between Spartina maritima and Arthrocnemum perenne. J Ecol 82:239-248

> Clarke SJ (2002) Vegetation growth in rivers: influences upon sediment and nutrient dynamics. Prog Phys Geogr 26: $159-172$

$>$ Crooks JA (2002) Characterizing ecosystem-level consequences of biological invasions: the role of ecosystem engineers. Oikos 97:153-166

Denny MW (1988) Biology and the mechanics of the wave- 
swept environment. Princeton University Press, Princeton, NJ

Fonseca MS, Fisher JS, Zieman JC, Thayer GW (1982) Influence of the seagrass, Zostera marina L., on current flow. Estuar Coast Shelf Sci 15:351-364

Gacia E, Duarte CM, Marba N, Terrados J, Kennedy H, Fortes MD, Tri NH (2003) Sediment deposition and production in SE-Asia seagrass meadows. Estuar Coast Mar Sci 56: 909-919

Gambi MC, Nowell ARM, Jumars PA (1990) Flume observations on flow dynamics in Zostera marina (eelgrass) beds. Mar Ecol Prog Ser 61:159-169

Ghisalberti M, Nepf HM (2002) Mixing layers and coherent structures in vegetated aquatic flows. J Geophys Res 107(C2):3-1-3-11 doi:10.1029/200IJC000871

Heiss WM, Smith AM, Probert PK (2000) Influence of the small intertidal seagrass Zostera novazelandica on linear water flow and sediment texture. N Z J Mar Freshw Res 34:689-694

Hemminga MA, Duarte CM (2000) Seagrass ecology. Cambridge University Press, Cambridge

> Hemminga MA, van Soelen J, Maas YEM (1998) Biomass production in pioneer Spartina anglica patches: evidence for the importance of seston particle deposition. Estuar Coast Shelf Sci 47:797-805

Hendriks IE, Sintes T, Bouma TJ, Duarte CM (2008) Experimental assessment and modelling evaluation of the effects of the seagrass Posidonia oceanica on flow and particle trapping. Mar Ecol Prog Ser 356:163-173

Jones CG, Lawton JH, Shachak M (1994) Organisms as ecosystem engineers. Oikos 69:373-386

> Jonsson PR, van Duren LA, Amielh M, Asmus R and others (2006) Making water flow: a comparison of the hydrodynamic characteristics of 12 different benthic biological flumes. Aquat Ecol 40:409-428

Koch EM (1996) Hydrodynamics of a shallow Thalassia testudinum bed in Florida. In: Kuo J, Phillips RC, Walker DI, Kirkman H (eds) Seagrass biology: proceedings of an international workshop. The University of Western Australia, Perth, p 105-109

Koch EM (2001) Beyond light: physical, geological, and geochemical parameters as possible submersed aquatic vegetation habitat requirements. Estuaries 24:1-17

Lacambra C, Cutts N, Allen J, Burd F, Elliott M (2004) Spartina anglica: a review of its status, dynamics and management. Engl Nat Res Rep No. 527, Inst Estuar Coast Stud, University of Hull

Langlois E, Bonis A, Bouzille JB (2003) Sediment and plant dynamics in saltmarshes pioneer zone: Puccinellia maritima as a key species? Estuar Coast Shelf Sci 56:239-249

Marba N, Duarte CM (1995) Coupling of seagrass (Cymodocea nodosa) patch dynamics to subaqueous dune migration. J Ecol 83:381-389

Marba N, Cebrian J, Enriquez S, Duarte CM (1994) Migration of large-scale subaqueous bedforms measured with seagrasses (Cymodocea nodosa) as tracers. Limnol Oceanogr 39:126-133

Mellors J, Marsh H, Carruthers TJB, Waycott M (2002) Testing the sediment-trapping paradigm of seagrass: Do seagrasses influence nutrient status and sediment structure in tropical intertidal environments? Bull Mar Sci 71: 1215-1226

Möller I, Spencer T, French JR, Leggett DJ, Dixon M (2001)

Editorial responsibility: Matthias Seaman,

Oldendorf/Luhe, Germany
The sea-defense value of salt marshes: field evidence from north Norfolk. J Chart Inst Water Environ Manag 15: $109-116$

> Nepf HM (1999) Drag, turbulence, and diffusion in flow through emergent vegetation. Water Resour Res 35: $479-489$

> Nepf HM, Vivoni ER (2000) Flow structure in depth-limited vegetated flow. J Geophys Res 105(C12):28547-28557

$>$ Neumeier U, Amos CL (2006) The influence of vegetation on turbulence and flow velocities in European salt-marshes. Sedimentology 53:259-277

> Neumeier U, Ciavola P (2004) Flow resistance and associated sedimentary processes in a Spartina maritima salt-marsh. J Coast Res 20:435-447

Peralta G, Brun FG, Hernández I, Vergara JJ, Pérez-Lloréns JL (2005) Morphometric variations as acclimation mechanisms in Zostera noltii beds. Estuar Coast Shelf Sci 64:347-356

Pérez-Lloréns JL, Niell FX (1993) Temperature and emergence on the net photosynthesis of two Zostera noltii Hornem. morphotypes. Hydrobiologia 254:53-64

Schenker N, Gentleman JF (2001) On judging the significance of differences by examining the overlap between confidence intervals. Am Stat 55:182-186

Stapel J, Aarts TL, van Duynhoven BHM, de Groot JD, van den Hoogen PHW, Hemminga MA (1996) Nutrient uptake by leaves and roots of the seagrass Thalassia hemprichii in the Spermonde Archipelago, Indonesia. Mar Ecol Prog Ser 134:195-206

> Touchette BW, Burkholder JM (2000a) Overview of the physiological ecology of carbon metabolism in seagrasses. J Exp Mar Biol Ecol 250:169-205

Touchette BW, Burkholder JM (2000b) Review of nitrogen and phosphorus metabolism in seagrasses. J Exp Mar Biol Ecol 250:133-167

Underwood AJ (1997) Experiments in ecology: their logical design and interpretation using analyses of variance. Cambridge University Press, Cambridge

van Hulzen JB, van Soelen J, Bouma TB (2007) Morphological variation and habitat modification are strongly correlated for the autogenic ecosystem engineer Spartina anglica (common cordgrass). Estuar Coast 30:3-11

van Katwijk MM, Hermus DCR, de Jong DJ, Asmus RM, de Jonge VN (2000) Habitat suitability of the Wadden Sea for restoration of Zostera marina beds. Helgol Mar Res 54: $117-128$

Vermaat JE, Agawin NSR, Fortes MD, Uri JS and others (1997) The capacity of seagrasses to survive increased turbidity and siltation: the significance of growth form and light use. Ambio 26:499-504

Vogel S (1994) Life in moving fluids: the physical biology of flow. Princeton University Press, Princeton, NJ

> Voulgaris G, Trowbridge JH (1998) Evaluation of the Acoustic Doppler Velocimeter (ADV) for turbulence measurements. J Atmos Ocean Technol 15:272-289

Wainwright SR, Biggs WD, Currey JD, Gosline JM (1976) Mechanical design in organisms. Wiley, New York

> Wang Q, An SQ, Ma ZJ, Zhao B, Chen JK, Li B (2006) Invasive Spartina alterniflora: biology, ecology and management. Acta Phytotaxon Sin 44:559-588

Widdows J, Brinsley M (2002) Impact of biotic and abiotic processes on sediment dynamics and the consequences to the structure and functioning of the intertidal zone. J Sea Res 48:143-156

Submitted: May 8, 2007; Accepted: May 15, 2008

Proofs received from author(s): September 17, 2008 